\title{
Temperature-responsive sensing regulates biocontrol factor expression in Pseudomonas fluorescens CHAO
}

\author{
Bérénice Humair, Nicolas González ${ }^{1}$, Dimitris Mossialos ${ }^{2}$, Cornelia Reimmann \\ and Dieter Haas \\ Département de Microbiologie Fondamentale, Université de Lausanne, Lausanne, Switzerland
}

\begin{abstract}
In the plant-beneficial, root-colonizing strain Pseudomonas fluorescens CHA0, the Gac/Rsm signal transduction pathway positively regulates the synthesis of biocontrol factors (mostly antifungal secondary metabolites) and contributes to oxidative stress response via the stress sigma factor RpoS. The backbone of this pathway consists of the GacS/GacA two-component system, which activates the expression of three small regulatory RNAs (RsmX, RsmY, RsmZ) and thereby counters translational repression exerted by the RsmA and RsmE proteins on target mRNAs encoding biocontrol factors. We found that the expression of typical biocontrol factors, that is, antibiotic compounds and hydrogen cyanide (involving the phIA and hcnA genes), was significantly lower at $35{ }^{\circ} \mathrm{C}$ than at $30 \mathrm{C}$. The expression of the rpoS gene was affected in parallel. This temperature control depended on RetS, a sensor kinase acting as an antagonist of the GacS/GacA system. An additional sensor kinase, LadS, which activated the GacS/GacA system, apparently did not contribute to thermosensitivity. Mutations in gacS or gacA were epistatic to (that is, they overruled) mutations in retS or ladS for expression of the small RNAs RsmXYZ. These data are consistent with a model according to which RetS-GacS and LadS-GacS interactions shape the output of the Gac/ Rsm pathway and the environmental temperature influences the RetS-GacS interaction in P. fluorescens CHAO.
\end{abstract}

The ISME Journal (2009) 3, 955-965; doi:10.1038/ismej.2009.42; published online 7 May 2009

Subject Category: microbe-microbe and microbe-host interactions

Keywords: biocontrol; GacS/GacA; Pseudomonas; RetS; small RNAs; temperature control

\section{Introduction}

Pseudomonas fluorescens CHA0, a model biocontrol bacterium originally isolated from a tobacco field in Switzerland, is an effective antagonist of plantpathogenic fungi and nematodes that cause root diseases. Like other biocontrol bacteria, strain CHA0 colonizes the rhizosphere of important crop plants and produces several antibiotic compounds and lytic exoenzymes, which are important biocontrol factors accounting for suppression of root diseases (Haas and Défago, 2005; Mark et al., 2006; Loper et al., 2007; Mercado-Blanco and Bakker, 2007). The expression of biocontrol factors depends on the Gac/

Correspondence: D Haas, Département de Microbiologie Fondamentale, Biophore, Université de Lausanne, CH-1015 Lausanne, Switzerland.

E-mail: Dieter.Haas@unil.ch

${ }^{1}$ Current address: Institut de Microbiologie, Université de Lausanne, Rue du Bugnon 48, CH-1011 Lausanne, Switzerland.

${ }^{2}$ Current address: Department of Biochemistry and Biotechnology, University of Thessaly, Ploutonos 26 and Eolou Street, GR-41221 Larissa, Greece.

Received 27 October 2008; revised 16 March 2009; accepted 17 March 2009; published online 7 May 2009
Rsm signal transduction pathway (Laville et al., 1992; Zuber et al., 2003). In this regulatory cascade, the GacS/GacA two-component system activates the transcription of three small RNAs (sRNAs) termed RsmX, RsmY and RsmZ when cells reach high population densities (Heeb et al., 2002; Valverde et al., 2003; Kay et al., 2005). These sRNAs avidly bind two sRNA-binding proteins belonging to the RsmA/CsrA family, named RsmA and RsmE (Reimmann et al., 2005). In this way, translational repression exerted by these proteins can be relieved and target mRNAs become accessible to ribosomes for translation (Valverde et al., 2004; Lapouge et al., $2007,2008)$. Typical target genes are, on the one hand, genes involved in biocontrol such as $\operatorname{hcn} A$ (for hydrogen cyanide (HCN) synthesis) and phlA (for synthesis of the antifungal metabolite 2, 4-diacetylphloroglucinol (DAPG)) and, on the other hand, the rpoS gene encoding the stress and stationary phase sigma factor $\sigma^{38}$, which is involved in the response of $P$. fluorescens to oxidative stress (Blumer et al., 1999; Heeb et al., 2005; Kay et al., 2005). Thus, mutants affected in the GacS/GacA two-component system produce dramatically reduced amounts of secondary metabolites and are 
more sensitive to hydrogen peroxide, compared to the wild type (Laville et al., 1992; Zuber et al., 2003; Heeb et al., 2005).

In pseudomonads, the activity of the Gac/Rsm pathway is regulated by autoinducing signal molecules whose chemical structures are unknown. These signals are thought to activate phosphorylation of the unorthodox GacS sensor (Heeb et al., 2002; Zuber et al., 2003; Dubuis et al., 2007). Phosphorylated GacS then activates the response regulator GacA via a phosphorelay mechanism, for which experimental evidence has been obtained in Pseudomonas aeruginosa (Goodman et al., 2009). In this organism, two additional sensors provide input into the Gac/Rsm pathway. These hybrid sensors termed RetS (for regulator of exopolysaccharide and type III secretion) and $\operatorname{Lad} \overline{\mathrm{S}}$ (for lost adherence) were discovered in screens for mutants that form increased or decreased amounts of biofilm polysaccharides. It has been shown that RetS inhibits and LadS activates the activity of the Gac/Rsm pathway (Goodman et al., 2004; Laskowski and Kazmierczak, 2006; Ventre et al., 2006). There is evidence that both RetS and LadS physically interact with GacS (Goodman et al., 2009; Workentine et al., 2009). However, the mechanisms by which these sensors communicate with one another and thereby determine the output of the system are not known. Moreover, the function of the Gac/Rsm pathway can be influenced by environmental cues. For instance, in Escherichia coli low $\mathrm{pH}$ values inhibit the activity of the BarA/UvrY proteins, which are GacS/GacA homologues (Mondragón et al., 2006).

In various biocontrol strains of $P$. fluorescens it has been observed that incubation temperatures around $35{ }^{\circ} \mathrm{C}$ have a negative effect on biocontrol efficacy in vivo and on the expression of biocontrol factors such as DAPG and phenazine-1-carboxylic acid in vitro (Shanahan et al., 1992; Slininger and SheaWilbur, 1995; Schmidt et al., 2004). We found that in strain CHA0, too, the production of antibiotic compounds and HCN was reduced at $35^{\circ} \mathrm{C}$, by comparison with the production at $30^{\circ} \mathrm{C}$. This suggested to us that some component of the Gac/Rsm pathway might be sensitive to elevated temperature. The aim of this study, therefore, was to find this component. This led us to examine the roles of the RetS and LadS sensors in strain CHA0; RetS was found to be involved in temperature control. Using a genetic approach, we show that mutations in gacS or gacA override the effects of mutations in retS or ladS. These findings are consistent with GacS interacting directly with RetS and LadS.

\section{Materials and methods}

Bacterial strains, plasmids and growth conditions The bacterial strains and plasmids are listed in Table 1. Strains of E. coli and P. fluorescens were grown in nutrient yeast broth (NYB) with shaking or on nutrient agar plates (Stanisich and Holloway, 1972). When required, antibiotics were added at the following concentrations: ampicillin (Ap), $100 \mu \mathrm{g} \mathrm{ml}^{-1}$ (only for E. coli); gentamicin (Gm), $10 \mu \mathrm{g} \mathrm{ml}^{-1}$; kanamycin (Km), $25 \mu \mathrm{g} \mathrm{ml}^{-1}$; tetracycline (Tc), $25 \mu \mathrm{g} \mathrm{ml}^{-1}$ (for E. coli) or $125 \mu \mathrm{g} \mathrm{ml}^{-1}$ (for $P$. fluorescens). In the mobilization of suicide plasmids (pME3087 derivatives) from $E$. coli to $P$. fluorescens, chloramphenicol $(\mathrm{Cm})$ at $10 \mu \mathrm{g} \mathrm{ml}^{-1}$ and Tc were used to select for the recipient having integrated the suicide plasmid. Enrichment for Tcsensitive strains, from which the suicide plasmid had been excised, was performed by exposing cells growing in NYB (at approximately $10^{8}$ cells per $\mathrm{ml}$ ) to Tc $\left(20 \mu \mathrm{g} \mathrm{ml}^{-1}\right)$ for $1 \mathrm{~h}$, followed by the addition of cycloserine $\left(1.6 \mathrm{mg} \mathrm{ml}^{-1}\right.$ ) and further incubation for $5 \mathrm{~h}$. For detection of lac $Z$ constructs, 5-bromo-4chloro-3-indolyl- $\beta$-D-galactopyranoside (X-gal) was added to plates at a final concentration of $0.02 \%$. Routine incubation temperatures were $30^{\circ} \mathrm{C}$ for $P$. fluorescens and $37^{\circ} \mathrm{C}$ for E. coli. Alternatively, $P$. fluorescens was grown at $35^{\circ} \mathrm{C}$ to test the temperature sensitivity of the Gac/Rsm signal transduction pathway and to improve its capacity to accept heterologous DNA originating from E. coli.

\section{DNA manipulation}

Small-scale plasmid extractions were done with the QIAprep Spin Miniprep Kit (Qiagen, Basel, Switzerland), whereas large-scale preparations were performed with the Jetstar kit (Genomed $\mathrm{GmbH}$, Basel, Switzerland). Chromosomal DNA from P. fluorescens was prepared as previously described (Gamper et al., 1992). DNA manipulations were carried out by standard techniques (Sambrook and Russell, 2001). DNA fragments were purified from agarose gels with the MinElute or QIAquick Gel extraction kits (Qiagen), depending on the fragment size. Electroporation of bacterial cells with plamid DNA was done as described (Farinha and Kropinsky, 1990). Conditions for amplifying PCR fragments were as follows: $200 \mathrm{ng}$ of genomic DNA was dissolved in a final volume of $20 \mu \mathrm{l}$ containing $200 \mu \mathrm{M}$ of each of the four dNTPs, $20 \mathrm{pmol}$ of each of two primers, $2 \mathrm{U}$ of GoTaq polymerase (Promega, Catalys, Wallisellen, Switzerland) and $1 \times$ GoTaq buffer (Promega). The PCR cycle was $2 \mathrm{~min}$ at $95^{\circ} \mathrm{C}$, $30 \times\left(45 \mathrm{~s}\right.$ at $95{ }^{\circ} \mathrm{C}, 45 \mathrm{~s}$ at $50-60^{\circ} \mathrm{C}$ (depending on the $\mathrm{G}+\mathrm{C}$ content and length of the primers), 0.5$2 \mathrm{~min}$ at $72{ }^{\circ} \mathrm{C}$ (depending on the length of the amplicon)) and a final elongation step of $5 \mathrm{~min}$ at $72{ }^{\circ} \mathrm{C}$. The reaction products were purified on an agarose gel and the purified fragments were sequenced with an automatic sequencer.

\section{Plasmid and strain constructions}

These were facilitated by the fact that strain CHAO is very similar to the completely sequenced strain Pf-5 
Table 1 Bacterial strains, plasmids and oligonucleotides used in this study

\begin{tabular}{|c|c|c|}
\hline $\begin{array}{l}\text { Strain, plasmid } \\
\text { or oligonucleotide }\end{array}$ & Genotype, phenotype or relevant characteristics & Reference or origin \\
\hline \multirow{2}{*}{\multicolumn{3}{|c|}{$\begin{array}{l}\text { Pseudomonas } \\
\text { fluorescens strains }\end{array}$}} \\
\hline & & \\
\hline CHA0 & Wild type & Voisard et al. (1994) \\
\hline CHA19 & $\Delta g a c S$ & Zuber et al. (2003) \\
\hline CHA19.8 & $\Delta$ gacS mini-Tn $7 \mathrm{Gm}^{\mathrm{r}}$ gacS $\Delta 76$ & Zuber et al. (2003) \\
\hline CHA89 & gac $A:: \mathrm{Km}^{\mathrm{r}}$ & Laville et al. (1992) \\
\hline CHA1202 & $\Delta r e t S$ & This study \\
\hline CHA1204 & $\Delta$ ladS & This study \\
\hline CHA1301 & $\Delta r e t S \Delta g a c S$ & This study \\
\hline CHA1302 & $\Delta$ ladS $\Delta$ gacS & This study \\
\hline CHA1303 & gacA::Km ${ }^{\mathrm{r}} \Delta r e t S$ & This study \\
\hline CHA1304 & gacA:: $\mathrm{Km}^{\mathrm{r}}$ DladS & This study \\
\hline CHA1305 & $\Delta$ retS $\Delta$ ladS & This study \\
\hline \multicolumn{3}{|l|}{ Plasmids } \\
\hline pBluescript-II KS & Cloning vector, ColE1-replicon; $\mathrm{Ap}^{\mathrm{r}}$ & Stratagene \\
\hline pME497 & Mobilizing plasmid; $\mathrm{Ap}^{\mathrm{r}}$ & Voisard et al. (1994) \\
\hline pME3087 & Suicide vector; ColE1-replicon, IncP-1, Mob; $\mathrm{Tc}^{\mathrm{r}}$ & Voisard et al. (1994) \\
\hline pME3280a & Mini-Tn7 gene delivery vector; $\mathrm{Gm}^{\mathrm{r}}$ & Zuber et al. (2003) \\
\hline pME6015 & Vector for translational 'lac $Z$ fusion; $\mathrm{Tc}^{\mathrm{r}}$ & Schnider-Keel et al. (2000) \\
\hline pME6091 & Transcriptional rsmZ-lacZ fusion; $\mathrm{Tc}^{\mathrm{r}}$ & Heeb et al. (2002) \\
\hline pME6182 & $\begin{array}{l}\text { Mini-Tn7 gene delivery vector based on pME3280a, HindIII-SmaI-KpnI-NcoI-SphI } \\
\text { MCS, ColE1 replicon; } \mathrm{Gm}^{\mathrm{r}} \mathrm{Ap}^{\mathrm{r}}\end{array}$ & This study \\
\hline pME6259 & Translational phlA'-'lacZ fusion, under phlA promoter; $\mathrm{Tc}^{\mathrm{r}}$ & Schnider-Keel et al. (2000) \\
\hline pME6355 & Translational $r p o S^{\prime}-{ }^{\prime} l a c Z$ fusion, under $r p o S$ promoter; $\mathrm{Tc}^{\mathrm{r}}$ & Heeb et al. (2005) \\
\hline pME6530 & 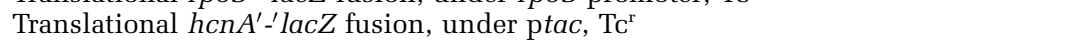 & Blumer et al. (1999) \\
\hline pME6702 & Translational $p h l A^{\prime}-{ }^{\prime} l a c Z$ fusion, under ptac, $\mathrm{Tc}^{\mathrm{r}}$ & Heeb et al. (2005) \\
\hline pME6916 & Transcriptional rsm Y-lacZ fusion; $\mathrm{Tc}^{\mathrm{r}}$ & Valverde et al. 2003) \\
\hline pME7317 & Transcriptional $r s m X$-lac $Z$ fusion; $\mathrm{Tc}^{\mathrm{r}}$ & Kay et al. (2005) \\
\hline pME7698 & pME6182 with a 3.5-kb fragment containing rsmX-lacZ; $\mathrm{Gm}^{\mathrm{r}} \mathrm{Ap}^{\mathrm{r}}$ & This study \\
\hline pME7699 & pME6182 with a 3.5-kb fragment containing rsmY-lacZ; $\mathrm{Gm}^{\mathrm{r}} \mathrm{Ap}^{\mathrm{r}}$ & This study \\
\hline pME7704 & $\begin{array}{l}\text { pBluescript-II KS containing a BamHI-EcoRI 620-bp retS upstream region and a } \\
\text { EcoRI-HindIII 640-bp retS downstream region; } \mathrm{Ap}^{\mathrm{r}}\end{array}$ & This study \\
\hline pME7705 & $\begin{array}{l}\text { BamHI-HindIII fragment (1.2 kb) of pME7704 cloned into BamHI-HindIII } \\
\text { digested pME3087 }\end{array}$ & This study \\
\hline pME7708 & $\begin{array}{l}\text { pBluescript-II KS containing a BamHI-EcoRI 575-bp ladS upstream region and a } \\
\text { EcoRI-HindIII 625-bp ladS downstream region; } \mathrm{Ap}^{\mathrm{r}}\end{array}$ & This study \\
\hline pME7709 & $\begin{array}{l}\text { BamHI-HindIII fragment (1.2 kb) of pME7708 cloned into BamHI-HindIII digested } \\
\text { pME3087 }\end{array}$ & This study \\
\hline pUC18 & Cloning vector; $\mathrm{Ap}^{\mathrm{r}}$ & Vieira and Messing (1991) \\
\hline pUX-BF13 & Helper plasmid containing Tn7 transposition functions, R6K replicon; $\mathrm{Ap}^{\mathrm{r}}$ & Bao et al. (1991) \\
\hline Oligonucleotides & $\left(5^{\prime} \rightarrow 3^{\prime}\right)$ & \\
\hline RetF1 & $\begin{array}{l}\text { TATGGATCCGGCCGAGGAAGGCAACGTCTA, with a BamHI underlined site, } \\
\text { located } 620 \mathrm{~b} p \text { upstream of the retS start codon }\end{array}$ & \\
\hline RetF2 & $\begin{array}{l}\text { TTATGAATTCCGAAATCCCTTCGTTGGTTGA, with an EcoRI underlined site, } \\
\text { located in the start codon region of retS }\end{array}$ & \\
\hline RetR1 & $\begin{array}{l}\text { TTATGAATTCCAGTTGAGCCGACAGGCTCTG, with an EcoRI underlined site, } \\
\text { located in the stop codon region of retS }\end{array}$ & \\
\hline RetR2 & $\begin{array}{l}\text { TATAAAGCTTGACCCCGGTGAAGATGATCTG, with a HindIII underlined site, } \\
\text { located } 640 \mathrm{bp} \text { downstream of the retS stop codon }\end{array}$ & \\
\hline RetN1 & ACCGCCTGGCGGCCGAGATC, located $190 \mathrm{bp}$ upstream of retS & \\
\hline RetN2 & GGCCCACGGTCAGGGGAATG, located $390 \mathrm{bp}$ downstream of retS & \\
\hline LadF1 & $\begin{array}{l}\text { ATATGGATCCGCATGGCGTAGCCGACTTCAT, with a BamHI underlined site, } \\
\text { located } 675 \mathrm{bp} \text { upstream of the ladS start codon }\end{array}$ & \\
\hline LadF2 & $\begin{array}{l}\text { TTATGAATTCCATAGCCGCTGATGGCCATTG, with an EcoRI underlined site, } \\
\text { located } 100 \mathrm{bp} \text { upstream the ladS start codon }\end{array}$ & \\
\hline LadR1 & $\begin{array}{l}\text { TTATGAATTCGGTCTTGGCACACCCTGAAG, with an EcoRI underlined site, } \\
\text { located } 35 \text { bp downstream of the ladS stop codon }\end{array}$ & \\
\hline LadR2 & $\begin{array}{l}\text { TATAAAGCTTGGTGGTGGCACGCACATC, with a HindIII underlined site, } \\
\text { located } 660 \mathrm{bp} \text { downstream of the ladS stop codon }\end{array}$ & \\
\hline LadN1 & GCGATCTGGCGCCTGCCAGC, located $230 \mathrm{bp}$ upstream of ladS & \\
\hline LadN2 & GGCGTCGACCCGCGACTCGG, located $200 \mathrm{bp}$ downstream of ladS & \\
\hline
\end{tabular}

Abbreviations: $\mathrm{Ap}^{\mathrm{r}}$, ampicillin resistance; $\mathrm{Gm}^{\mathrm{r}}$, gentamicin resistance; $\mathrm{MCS}$, multiple cloning site; $\mathrm{Tc}^{\mathrm{r}}$, tetracycline resistance. 
of P. fluorescens (Paulsen et al., 2005; Loper et al., 2007). To generate the retS mutant CHA1202, a 2.8-kb fragment was deleted in-frame in the chromosomal retS gene. For this purpose, a 620-bp BamHI-EcoRI fragment upstream of retS was amplified by PCR from strain CHA0, using primers RetF1 and RetF2. A 640-bp EcoRI-HindIII fragment including the last $9 \mathrm{bp}$ of retS and the adjacent downstream region was amplified by PCR with primers RetR1 and RetR2. The resulting upstream and downstream fragments were cloned by a triple ligation into pBluescript II KS digested with BamHI and HindIII, giving plasmid pME7704 (Table 1). The 1.2-kb BamHI-HindIII insert was excised and cloned into the suicide plasmid pME3087 digested with BamHI and HindIII, producing pME7705 (Table 1). This plasmid was integrated into the chromosome of strain CHAO by triparental mating, using E. coli HB101/pME497 as the mobilizing strain. Clones, in which excision of the vector by a second crossingover event had occurred, were isolated after enrichment for tetracycline-sensitive cells. The $\Delta$ retS mutation in the recombinant strain was verified by PCR using primers RetN1 and RetN2.

An analogous gene replacement strategy was followed to create a $2.5-\mathrm{kb}$ ladS deletion in strain CHA1204. Using CHAO DNA as a template, fragments flanking the ladS gene were amplified by PCR with primer pairs LadF1-LadF2 and LadR1-LadR2, respectively. The 575-bp upstream and 625-bp downstream fragments obtained were digested with BamHI-EcoRI and with EcoRI-HindIII, respectively, and cloned into BamHI-HindIII-digested pBluescript II KS, resulting in plasmid pME7708 (Table 1). The 1.2-kb BamHI-HindIII insert was excised from pME7708 and cloned into pME3087 digested with the same restriction enzymes, giving plasmid pME7709 (Table 1), which served to delete the ladS gene in strain CHA1204. The $\Delta$ ladS mutation in the recombinant strain was verified by PCR using primers LadN1 and LadN2.

The $\Delta$ retS $\Delta$ ladS double mutant CHA1305 was obtained by using the suicide plasmid pME7705 to delete the retS gene in the ladS mutant CHA1204. The $\Delta$ retS $\Delta$ gacS double mutant CHA1301 (Table 1) was obtained similarly in the gacS mutant CHA19. The $\Delta$ ladS $\Delta$ gacS double mutant CHA1302 (Table 1) was obtained by using the suicide plasmid pME7709 to delete the ladS gene in the gacS mutant CHA19. Likewise, pME7705 and pME7709 were used to delete retS and ladS in the $\operatorname{gac} A:: \mathrm{Km}^{\mathrm{r}}$ mutant CHA89, generating the gacA:: $\mathrm{Km}^{\mathrm{r}} \Delta \mathrm{retS}$ and the gacA::Km ${ }^{\mathrm{r}}$ sladS double mutants CHA1303 and CHA1304, respectively (Table 1). The retS and ladS mutations were verified by PCR.

The mini-Tn7-Gm carrier plasmid pME6182 is a derivative of the previously described Tn7-delivery vector pME3280a (Zuber et al., 2003), which carries transcription stop signals at both ends of its multiple cloning site. It was generated in several steps. First, a 0.36-kb BfrI-SalI fragment carrying the transcrip- tion stop signal located between the $P$. aeruginosa pchDCBA operon and the downstream ssb gene (http//www.pseudomonas.com) was cloned between the PstI and SalI sites of pUC18; the BfrI and PstI ends were made compatible by T4 DNA polymerase treatment. The transcription stop signal was then excised as 0.36-kb SphI-XbaI fragment and inserted between the SphI and SpeI sites of the pME3280a polylinker. To generate the chromosomal insertion of $r s m X-l a c Z$, a 3.5-kb rsmX-lacZ fusion fragment was first recovered by digesting pME7317 with EcoRI and XhoI, blunted (with $5 \mathrm{U}$ T4-DNA polymerase (Promega), $100 \mu \mathrm{M}$ dNTPs, $20 \mathrm{~min}$ at room temperature), and cloned into plasmid pME6182 digested with SmaI. The resulting plasmid pME7698 and the Tn7 transposition helper plasmid pUX-BF13 were then coelectroporated into different recipient strains, with selection for the mini-Tn7. Likewise, the chromosomal insertion of rsm Y-lacZ was constructed by digesting pME6916 with EcoRI and XhoI to recover a 3.5-kb rsmY-lacZ fusion fragment, which was blunted and cloned into the plasmid pME6182 digested with SmaI. The construct obtained, pME7699, and pUX-BF13 were coelectroporated into different recipient strains.

\section{Antibiotic and HCN assays}

Antibiotic production by strain CHAO was assessed with Bacillus subtilis $168 \mathrm{M}$ as the indicator as described by Dubuis and Haas (2007) on plates containing, per liter, $10 \mathrm{~g}$ proteose peptone, $4.6 \mathrm{~g}$ glycerol, $0.75 \mathrm{~g} \mathrm{~K}_{2} \mathrm{HPO}_{4}, 0.75 \mathrm{~g} \mathrm{MgSO}_{4} \cdot 7 \mathrm{H}_{2} \mathrm{O}, 27 \mathrm{mg}$ $\mathrm{FeCl}_{3} \cdot 6 \mathrm{H}_{2} \mathrm{O}$ and $20 \mathrm{~g}$ agar (pH 7.0). HCN concentrations in culture supernatants were determined after oxygen-limited growth in NYB according to a protocol previously described (Kay et al., 2006).

\section{$\beta$-Galactosidase assays}

$P$. fluorescens strains containing lacZ constructs were grown in $20 \mathrm{ml}$ NYB (amended with $0.05 \%$ (vol/vol) Triton X-100) in 100-ml Erlenmeyer flasks with shaking. $\beta$-Galactosidase activities were quantified by the method of Miller (1972), using cells permeabilized with 5\% (vol/vol) toluene. All experiments were performed in triplicate.

\section{Results}

Temperature sensitivity of the Gac/Rsm pathway In rich liquid medium (NYB) and during exponential growth, strain CHAO had a similar doubling time (33 $\pm 1 \mathrm{~min})$ at $30^{\circ} \mathrm{C}$ as well as at $35^{\circ} \mathrm{C}$. No growth occurred above $37^{\circ} \mathrm{C}$. At an incubation temperature of $35{ }^{\circ} \mathrm{C}, P$. fluorescens CHA0 produced only a small amount of antibiotic compounds on rich solid medium, as revealed by a small inhibition zone using a $B$. subtilis overlay. By contrast, at the standard incubation temperature of $30{ }^{\circ} \mathrm{C}$, antibiotic production was markedly stronger. We presume that 
the antibiotics that are produced under these conditions include DAPG as a major component. We also noted that strain CHA0 produced less HCN at $35{ }^{\circ} \mathrm{C}$ than at $30^{\circ} \mathrm{C}$. Antibiotic and HCN data will be shown in the last section of Results. The expression of the $h c n A$ and phlA genes involved in the biosynthesis of HCN and DAPG, respectively, revealed the extent of temperature sensitivity. This was seen with translational hcn $A^{\prime}$ - $^{\prime} l a c Z$ and $p h l A^{\prime}$ 'lacZ fusions (Figures 1a and b). An rpos' 'lacZ $^{\prime}$ fusion was also tested and found to be less active at $35{ }^{\circ} \mathrm{C}$ than at $30^{\circ} \mathrm{C}$ (Figure 1c). Together, these results suggested that it might be the Gac/Rsm pathway that responds to temperature as an environmental cue. This hypothesis was confirmed by

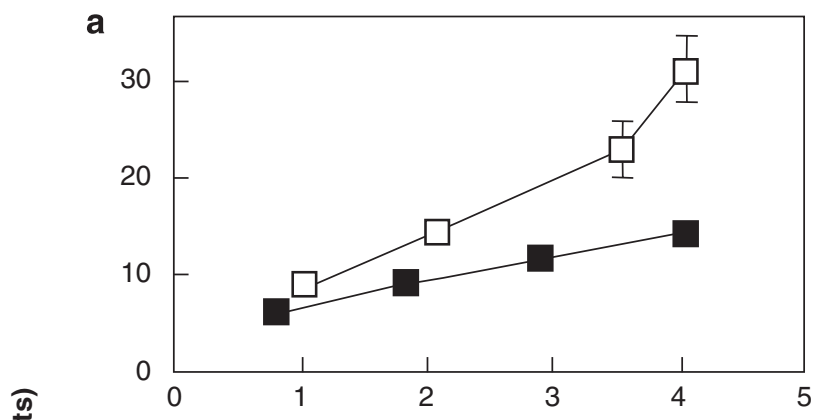

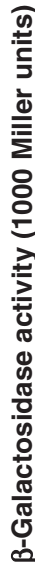

\section{b}

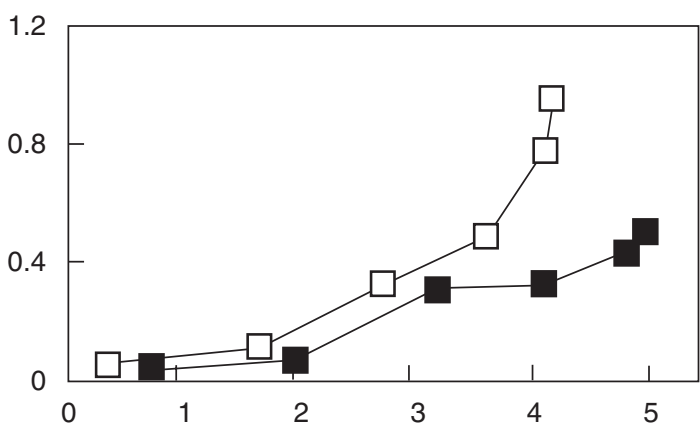

c

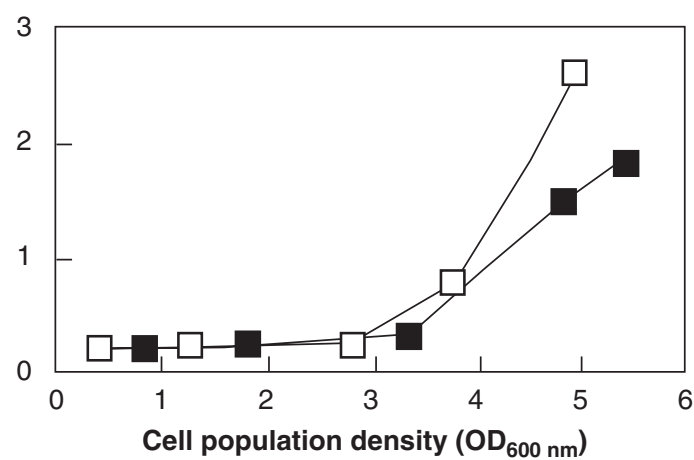

Figure 1 Expression of target genes of the Gac/Rsm cascade in the wild-type CHA0 as a function of growth temperature. Strains were grown in nutrient yeast broth (NYB) at 30 or $35^{\circ} \mathrm{C}$ $\beta$-Galactosidase activities were determined for (a) a ptac-hcn $A^{\prime}$ 'lacZ fusion (on pME6530), (b) a phlA'-'lacZ fusion (on pME6259) and (c) an rpoS ${ }^{\prime}{ }^{\prime} l a c Z$ fusion (on pME6355). $\square$, wild type at $30^{\circ} \mathrm{C}$; $\mathbf{\square}$, wild type at $35^{\circ} \mathrm{C}$. Experiments were done three times; each value is the average \pm standard deviation. the observation that the expression of transcriptional lacZ fusions to the $\operatorname{rsm} Z, \operatorname{rsm} Y$ and $\operatorname{rsm} X$ sRNA genes was lower at $35^{\circ} \mathrm{C}$ than that found at standard $30^{\circ} \mathrm{C}$ in NYB medium (Figures 2a-C). Note that strain CHAO did not tolerate fully induced expression of the rsm Y-lacZ and rsmX-lacZ fusions when these were carried by plasmids having about six copies. In our experience, it is difficult to detect specific activities exceeding 40000 Miller units, which were the activities found at the end of growth in the wild type carrying pME6916 (rsmY-lacZ) or pME7317 (rsmX-lacZ; data not shown). To overcome this problem, these fusions were introduced into the

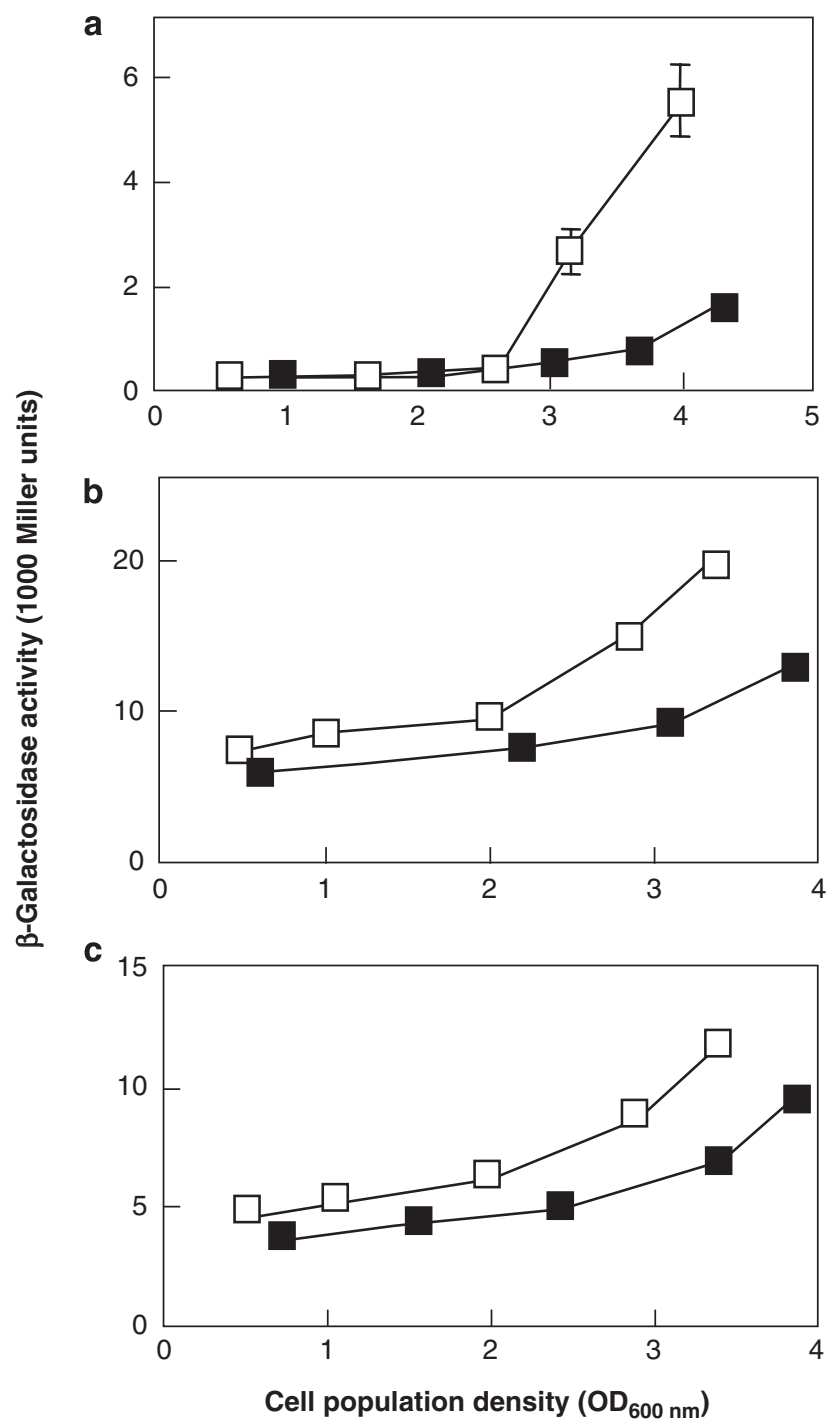

Figure 2 Influence of the growth temperature on transcriptional expression of the small regulatory RNAs RsmZ, RsmY and RsmX in the wild-type CHA0. Strains were grown in nutrient yeast broth (NYB) at 30 or $35^{\circ} \mathrm{C}$. $\beta$-Galactosidase activities were determined for (a) a plasmid-borne chromosomal rsmZ-lacZ fusion (on pME6091), (b) a chromosomal rsmY-lacZ fusion and (c) a chromosomal $\operatorname{rsm} X$-lac $Z$ fusion. $\square$, wild type at $30^{\circ} \mathrm{C}$; $\mathbf{\square}$, wild type at $35^{\circ} \mathrm{C}$. Experiments were done three times; each value is the average \pm standard deviation. 
chromosomal Tn7 attachment site, whereas $\mathrm{rsm} Z$ lacZ was assessed on a plasmid construct.

RetS as a temperature-sensitive element

To test which component of the Gac/Rsm pathway was responsible for the temperature effect, we first tested the rsmZ-lacZ fusion in the gacS $\Delta 76$ mutant CHA19.8, which expresses GacA-dependent genes at constitutive high levels (Zuber et al., 2003). However, the rsmZ-lacZ construct displayed no temperature sensitivity (data not shown), indicating that the activities of the GacS sensor and the GacA response regulator were not compromised at high temperature. This led us to inspect the potential

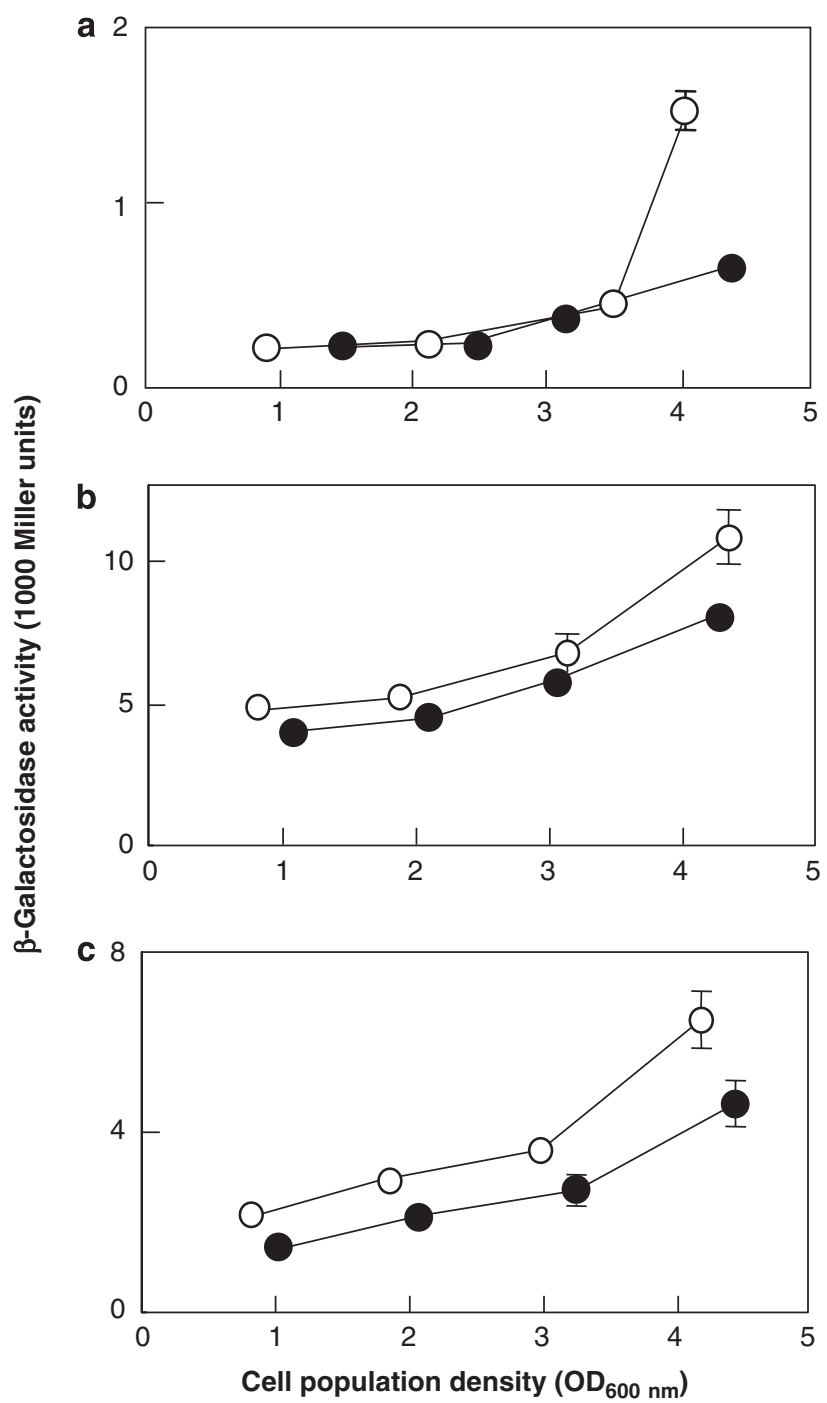

Figure 3 Influence of the growth temperature on transcriptional expression of the small regulatory RNAs RsmZ, RsmY and RsmX in a ladS mutant. Strains were grown in nutrient yeast broth (NYB) at 30 or $35^{\circ} \mathrm{C}$. $\beta$-Galactosidase activities were determined for (a) a plasmid-borne rsmZ-lacZ fusion (on pME6091), (b) a chromosomal rsm Y-lacZ fusion and (c) a chromosomal rsmX-lacZ fusion. $\bigcirc$, ladS mutant at $30^{\circ} \mathrm{C}$; $\bigcirc$, ladS mutant at $35^{\circ} \mathrm{C}$. Experiments were done three times; each value is the average \pm standard deviation. influence of the two accessory sensors LadS and RetS, which had previously been described in $P$. aeruginosa (Goodman et al., 2004, 2009; Laskowski and Kazmierczak, 2006; Ventre et al., 2006). To this end, we constructed mutants deleted for ladS (PFL_5426 in the closely related strain Pf-5) or retS (PFL_0664 in strain P. fluorescens Pf-5) in the wildtype $P$. fluorescens CHA0. In a ladS mutant, the lacZ fusions to $\operatorname{rsm} Z, \operatorname{rsm} Y$ and $\operatorname{rsm} X$ were all expressed at levels (Figures $3 \mathrm{a}-\mathrm{c}$ ) that were roughly half of those found in the wild type (Figures 2a-c). However, in the ladS background temperature sensitivity essentially persisted (Figure 3). By contrast, in a retS mutant, temperature sensitivity was lost and all three fusion constructs were expressed at high levels, well above those observed in the wild type (Figures $4 \mathrm{a}-\mathrm{C}$ ). In a retS ladS double mutant,
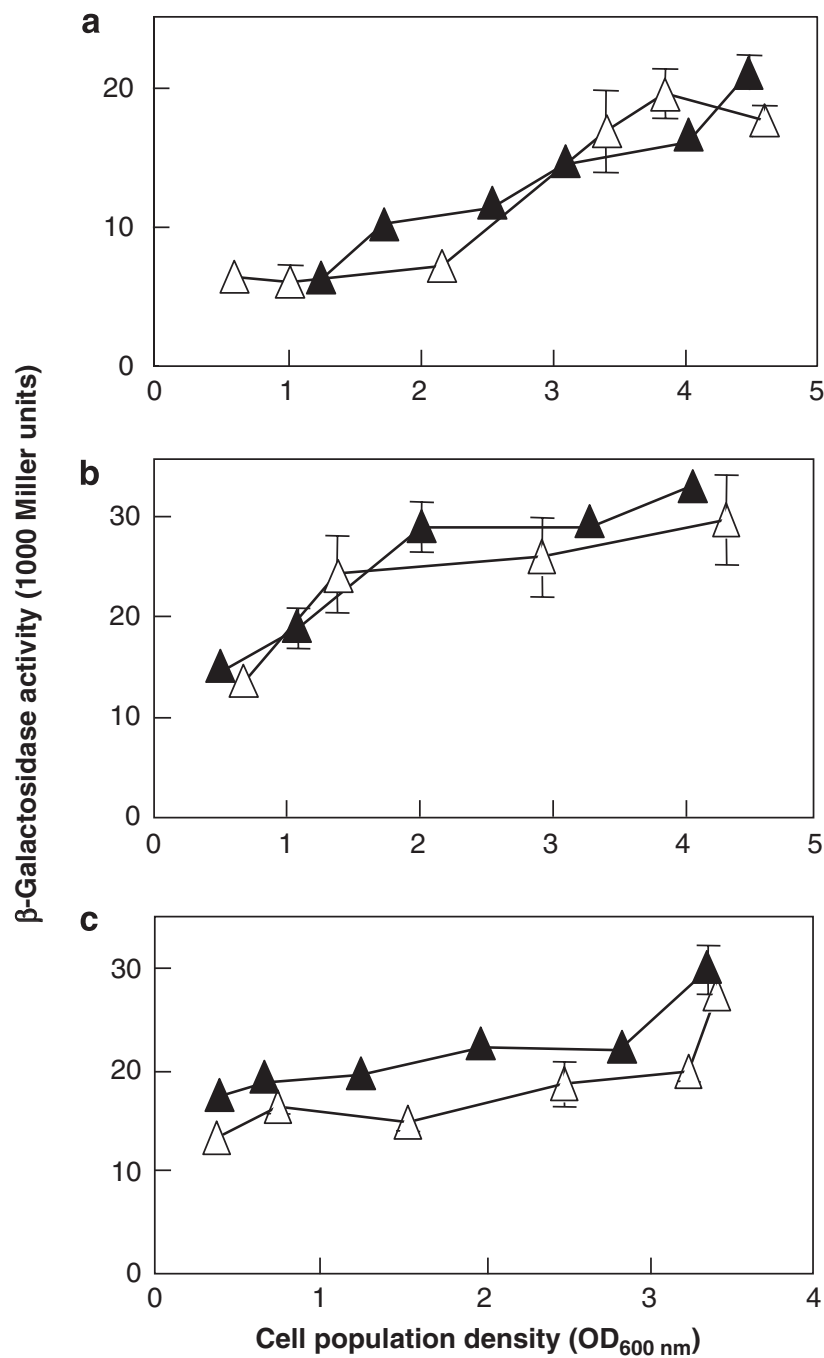

Figure 4 Influence of the growth temperature on transcriptional expression of the small regulatory RNAs RsmZ, RsmY and RsmX in a retS mutant. Strains were grown in nutrient yeast broth (NYB) at 30 or $35^{\circ} \mathrm{C}$. $\beta$-Galactosidase activities were determined for (a) a plasmid-borne rsmZ-lacZ fusion (on pME6091), (b) a chromosomal rsm Y-lacZ fusion and (c) a chromosomal rsmX-lacZ fusion. $\triangle$, retS mutant at $30^{\circ} \mathrm{C} ; \boldsymbol{\Delta}$, retS mutant at $35^{\circ} \mathrm{C}$. Experiments were done three times; each value is the average \pm standard deviation. 
the same result was obtained as in a retS mutant (data not shown). A control experiment using a transcriptional lac $Z$ fusion to the constitutive tac promoter confirmed that transcription per se was not compromised at $35^{\circ} \mathrm{C}$ (data not shown). Taken together, these results indicate that LadS and RetS have positive and negative effects, respectively, on the Gac/Rsm cascade of P. fluorescens CHAO and that temperature sensitivity depends essentially on RetS.

Mutations in gacS or gacA are epistatic to mutations in ladS and retS

Recent studies indicate that LadS and RetS physically interact with GacS (Goodman et al., 2009; Workentine et al., 2009). The following experiments lend support to these findings. The expression of rsm $Z$, rsm $Y$ and $r s m X$ was very low in both gacS and gacA mutants of strain CHA0, compared with the wild type, in agreement with previous results (Kay et al., 2005). In ladS gacS, ladS gacA, retS gacS and retS gacA double mutants, the expression of the three sRNA genes was equally low (Supplementary Figure S1). By contrast, as shown above (Figures 24), in a simple ladS background all reporter fusions were expressed at levels that were intermediate between the basal (gacS or gacA) level and the wildtype level, whereas very high levels occurred in a simple retS mutant. Thus, LadS and RetS functioned as modulators of the Gac/Rsm pathway in P. fluorescens CHA0. The fact that gacS and gacA mutations were epistatic to retS and ladS mutations are in agreement with a model in which RetS and LadS make contacts with GacS.

\section{A retS mutant shows diminished temperature} regulation of biocontrol factor expression If RetS-GacS interaction is regulated by temperature, we would expect that in a retS mutant high temperature should have little or no effect on the expression of biocontrol factors. This was the case. The expression of translational lac $Z$ fusions to the $h c n A$ and phlA target genes was consistent with the expression of the $\operatorname{rsm} Z, \operatorname{rsm} Y$ and $\operatorname{rsm} X$ sRNA genes: a ladS mutation lowered the expression, whereas a retS mutation increased the expression of these lac $Z$ fusions (Supplementary Figure S2), although the hcn $A^{\prime}$-' lacZ reporter on plasmid pME6530 could not be measured in the ret $S$ mutant, because $\beta$-galactosidase levels were above the tolerated upper limit. The translational expression of rpoS also followed the same pattern (Supplementary Figure S2). Antibiotic production was enhanced in the retS mutant CHA1202, relative to that found in the wild type. This effect was most pronounced at $35^{\circ} \mathrm{C}$ where the wild type had low antibiotic activity, as revealed by a small zone of inhibition of $B$. subtilis (Figure 5). The effects of the ladS mutation on antibiotic production (Figure 5) were also consistent with a

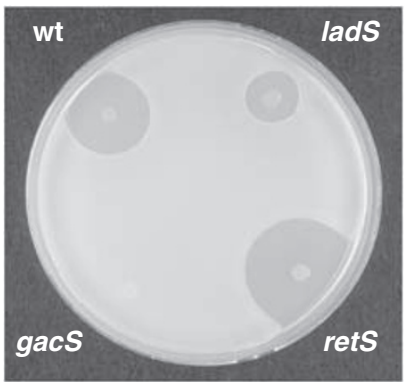

b

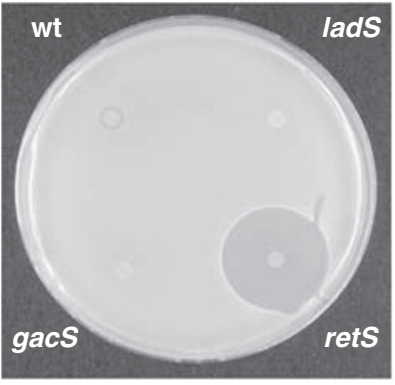

Figure 5 Influence of the growth temperature on the production of antibiotics in the Pseudomonas fluorescens wild-type strain CHA0, the retS mutant CHA1202, the ladS mutant CHA1204 and the gacS mutant CHA19. Antibiotic production was assessed by spotting 2- $\mu \mathrm{l}$ samples of an overnight culture (adjusted to $\mathrm{OD}_{600}=2.0$ ) onto solid plates (see Materials and methods). After incubation at $30^{\circ} \mathrm{C}(\mathbf{a})$ or $35^{\circ} \mathrm{C}$ (b) for $12-14 \mathrm{~h}$, P. fluorescens was killed by UV irradiation and Bacillus subtilis strain $168 \mathrm{M}$ was overlaid in $0.5 \%$ nutrient yeast broth (NYB) agar. Plates were incubated at $30^{\circ} \mathrm{C}$ until inhibition halos appeared.

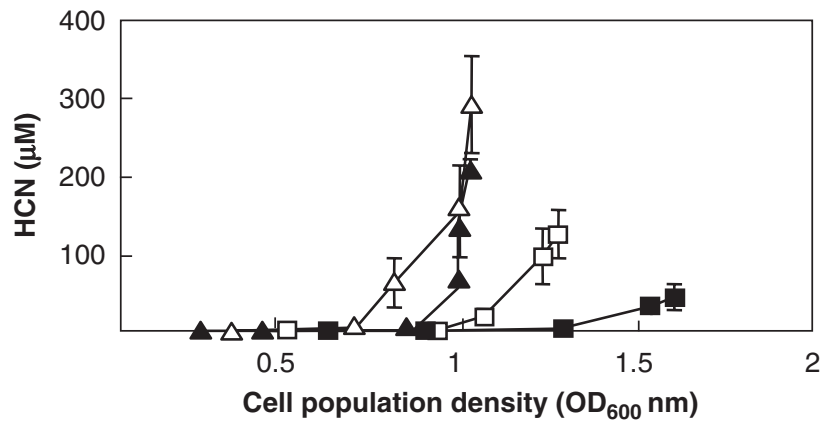

Figure 6 Influence of the growth temperature on hydrogen cyanide (HCN) production in the Pseudomonas fluorescens wildtype strain CHA0 and in the retS mutant CHA1202. HCN production was measured in nutrient yeast broth (NYB) medium in which $P$. fluorescens had been grown with oxygen limitation. $\square$, wild type at $30^{\circ} \mathrm{C}$; $\mathbf{\square}$, wild type at $35^{\circ} \mathrm{C} ; \triangle$, retS mutant at $30{ }^{\circ} \mathrm{C} ; \boldsymbol{\Delta}$, retS mutant at $35^{\circ} \mathrm{C}$. Experiments were done five times; each value is the average \pm standard deviation.

sRNA expression data (Figure 3). Finally, HCN production was enhanced and advanced in the retS mutant both at $30{ }^{\circ} \mathrm{C}$ and at $35^{\circ} \mathrm{C}$, whereas in the wild-type HCN formation was delayed and strongly reduced at $35^{\circ} \mathrm{C}$ (Figure 6). The model shown in Figure 7 summarizes the findings and will be presented in Discussion.

\section{Discussion}

The principal aim of this study was to shed light on the mechanism involved in thermoregulation of biocontrol factor expression in $P$. fluorescens CHA0. In precedent work on various biocontrol strains of $P$. fluorescens phenotypic evidence had been obtained for this type of regulation (Shanahan et al., 1992; Slininger and Shea-Wilbur, 1995; Schmidt et al., 2004), but the mode of action 


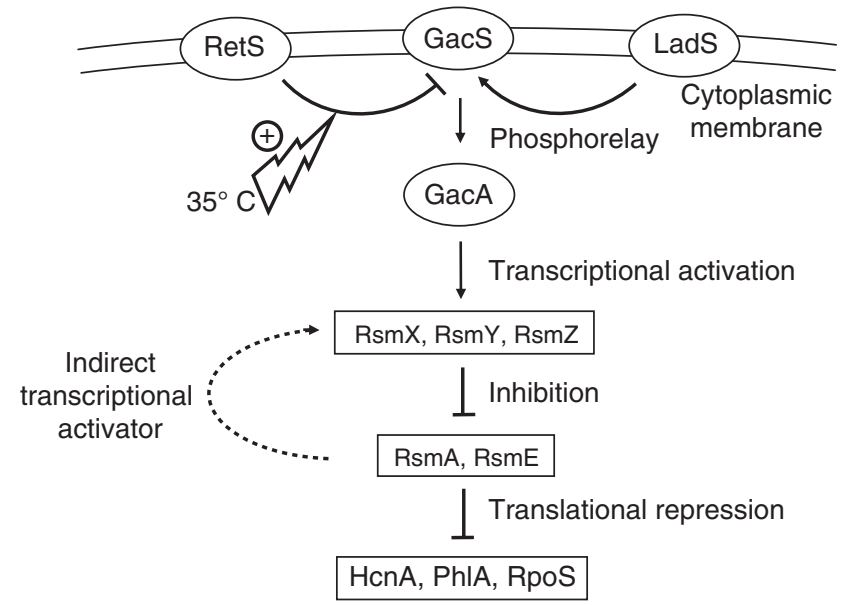

Figure 7 Integrative model of the Gac/Rsm signal transduction pathway in Pseudomonas fluorescens CHA0. $\downarrow$, positive control; $\perp$, negative control; dotted lines, indirect control. Evidence for this pathway comes from this work and from previous studies (Heeb et al., 2002, 2005; Valverde et al., 2003; Kay et al., 2005; Reimmann et al., 2005).

remained unknown. Our observation that key regulatory elements, the sRNA genes $\operatorname{rsmX}$, rsmY and $\operatorname{rsm} Z$, all showed diminished transcription at $35{ }^{\circ} \mathrm{C}$, relative to that seen at the standard growth temperature of $30^{\circ} \mathrm{C}$ (Figure 2), led to the hypothesis that some component of the Gac/Rsm signal transduction pathway might be temperature-sensitive. We found that a retS mutant had lost temperature sensitivity and expressed the sRNA genes at constitutive high levels (Figure 4). This finding suggests that RetS activity is influenced by temperature and that the GacS/GacA two-component system itself remains fully functional at elevated temperature. The ecological significance of temperature-sensitive expression of biocontrol factors is speculative at the moment. If we admit that the production of biocontrol traits normally confers a selective advantage on the producer strains (Haas and Keel, 2003), then we can assume that this advantage may not be relevant at temperatures around $35^{\circ} \mathrm{C}$ where the growth of many competing soil microorganisms including some pathogenic fungi is inhibited. Under these conditions, $P$. fluorescens can conceivably afford to dedicate its metabolic energy essentially to primary metabolism, without having to pay the full cost of secondary metabolism, which is necessary for producing biocontrol factors.

We also tested $\mathrm{pH}$ as a potential cue, as a previous study (Mondragón et al., 2006) had shown $\mathrm{pH}$ sensitivity of the BarA/UvrY two-component system in E. coli. However, at $\mathrm{pH} 6.2$, the lowest $\mathrm{pH}$ value allowing good growth of strain CHA0, the expression of lacZ fusions to $r s m Z, r s m Y$ and $r s m X$ was similar to that measured at standard neutral $\mathrm{pH}$ (data not shown).

The specificity of the GacS-GacA interaction has previously been substantiated by genetic analyses conducted in several Pseudomonas species (Rich et al., 1994; Heeb and Haas, 2001) and by biochemical evidence for phosphotransfer between a soluble form of GacS and GacA in P. aeruginosa (Goodman et al., 2009). In $P$. aeruginosa, the LadS and RetS sensors have been reported to modify the activity of the GacS/GacA system in vivo (Goodman et al., 2004; Laskowski and Kazmierczak, 2006; Ventre et al., 2006). LadS contains eight putative transmembrane segments, an autophosphorylation (kinase) domain and a response regulator domain. Mutation of the ladS gene strongly diminished $r s m Z$ expression (rsm $Y$ expression was not tested) and resulted in reduced production of adhesive extracellular polysaccharides and enhanced expression of the type III secretion apparatus in P. aeruginosa (Ventre et al., 2006). Thus, LadS appears to activate the GacS/GacA system although the mechanism by which this effect is brought about has not been elucidated. In P. fluorescens CHA0, there is evidence that LadS and GacS may interact physically (Workentine et al., 2009). As we have shown here, LadS positively controls $r s m X, r s m Y$ and $r s m Z$ expression, albeit less strongly than GacS (Figures 2, 3; Supplementary Figure S2). As both gacS and gacA mutations were epistatic to a ladS mutation (Supplementary Figure S1), it is likely that LadS acts upstream of GacS. This might be achieved if LadS physically interacted with GacS and thereby facilitated autophosphorylation of GacS (see model in Figure 7). A direct interaction between LadS and GacA appears less plausible as in this case the expression of the three sRNAs should be more strongly affected by the double ladS gacS mutation than by single ladS or gacS mutations; however, this was not observed (Supplementary Figure S1).

The RetS sensor of $P$. aeruginosa also contains eight putative transmembrane segments, a kinase domain and an adjacent response regulator domain. However, RetS has an additional response regulator domain located at the $\mathrm{C}$ terminus, and this domain is most important for biological activity. A retS mutant of $P$. aeruginosa overexpressed $\operatorname{rsm} Z$ and biofilm exopolysaccharides and had a downregulated type III secretion apparatus; $r s m Y$ expression was not tested (Goodman et al., 2004; Laskowski and Kazmierczak, 2006). Mutation in gacS was found to be epistatic to mutation in retS (Goodman et al., 2004). RetS acts as an antagonist of GacS in vitro (Goodman et al., 2009). In P. fluorescens CHA0, we found that the RetS homologue had a negative effect on the expression of all three GacAcontrolled sRNA genes, $\operatorname{rsmX}, \quad r s m Y$ and $r s m Z$ (Figures 2 and 4). Consequently, a retS mutation resulted in strongly enhanced promoter activities of the three sRNA genes and hence the expression of target genes and of biocontrol factors was strongly elevated as well (Figures 5, 6; Supplementary Figure S2). These data are consistent with a model of direct RetS-GacS interaction (Figure 7), for which there is in vivo evidence in strain CHA0 (Workentine et al., 
2009). However, the biochemistry of the antagonistic interaction between RetS and GacS is still uncertain. It has been postulated that RetS could have phosphatase activity on GacS (Laskowski and Kazmierczak, 2006), but this has not been confirmed in vitro (Goodman et al., 2009). There are precedents of interacting membrane sensor proteins: various dimeric chemoreceptor proteins of enteric bacteria are known to assemble as trimers in the cytoplasmic membrane, allowing the bacteria to integrate several signals in the chemotactic response (Hazelbauer et al., 2008). Note that the model shown in Figure 7 differs from another recently published model in which GacS, LadS and RetS are all assumed to interact with GacA in P. aeruginosa (Gooderham and Hancock, 2009).

Temperature is an important environmental cue. Some bacteria can sense it via transmembrane sensor kinases other than RetS. For example, a temperature-responsive sensor regulates the production of the chlorosis-inducing toxin coronatine in the soybean pathogen Pseudomonas syringae pv. glycinea PG4180. Toxin production occurs at $18^{\circ} \mathrm{C}$ but not at $28{ }^{\circ} \mathrm{C}$, the optimal growth temperature (Palmer and Bender, 1993). This thermoregulation is mediated at the transcriptional level by a regulatory system consisting of a histidine protein kinase, CorS, and two transcriptional activators, CorR and CorP. The C-terminal cytosolic region of CorS appears to act as a temperature sensor; it is believed to respond to intracellular temperature changes via autophosphorylation and to transduce the signal to the response regulator CorR via phosphorylation (Braun et al., 2008). Another example is provided by the thermal control of fatty acid synthesis. The fraction of unsaturated phospholipid acyl chains in phospholipids increases when the growth temperature decreases. This adaptation improves membrane fluidity. In $B$. subtilis, a two-component system composed of a membrane-associated kinase, DesK, and a soluble transcriptional activator, DesR, regulates the transcription of the des gene coding for a $\Delta^{5}$-fatty acid desaturase. DesK is a sensor having both kinase and phosphatase activities. At $37^{\circ} \mathrm{C}$, when membrane lipids are in a disordered fluid state, the phosphatase mode of DesK is dominant. After a temperature downshift to $25^{\circ} \mathrm{C}$, the proportion of ordered membrane lipids (that is, a nonfluid state) predominates, leading to an increase of the kinase mode of DesK. This results in autophosphorylation and transfer of the phosphoryl group to DesR. Phosphorylated DesR activates transcription of des, and the Des enzyme introduces a double bond into the acyl chains of membrane phospholipids (Aguilar et al., 2001). Experimental evidence points to membrane fluidity being a stimulus of the $\mathrm{N}$-terminal transmembrane domain of DesK (Hunger et al., 2004).

In this study, we have shown that $\operatorname{RetS}$ is a stronger antagonist of $\mathrm{GacS}$ at $35^{\circ} \mathrm{C}$ than at $30^{\circ} \mathrm{C}$. This mechanism of temperature sensing might involve a change in membrane fluidity, enabling a stronger contact between the two sensors at $35^{\circ} \mathrm{C}$. Previous observations in Pseudomonas species have indeed suggested that changes of membrane fluidity can modify quorum sensing regulation (Baysse and O’Gara, 2007).

\section{Acknowledgements}

This work was supported by the Swiss National Foundation (project 3100A0-100180) and, in part, by a genomics project of the University of Lausanne.

\section{References}

Aguilar PS, Hernandez-Arriaga AM, Cybulski LE, Erazo AC, de Mendoza D. (2001). Molecular basis of thermosensing: a two-component signal transduction thermometer in Bacillus subtilis. EMBO $J$ 20: 1681-1691.

Bao Y, Lies DP, Fu H, Roberts GP. (1991). An improved Tn7-based system for the single-copy insertion of cloned genes into chromosomes of gram-negative bacteria. Gene 109: 167-168.

Baysse C, O'Gara F. (2007). Role of membrane structure during stress signalling and adaptation in Pseudomonas. In: Ramos JL, Filloux A (eds). Pseudomonas vol. 5. Springer: Heidelberg, Germany. pp 193-224.

Blumer C, Heeb S, Pessi G, Haas D. (1999). Global GacAsteered control of cyanide and exoprotease production in Pseudomonas fluorescens involves specific ribosome binding sites. Proc Natl Acad Sci USA 96: 14073-14078.

Braun Y, Smirnova AV, Schenk A, Weingart H, Burau C, Muskhelishvili G et al. (2008). Component and domain exchange analysis of a thermosensitive, two-component regulatory system of Pseudomonas syringae. Microbiology 154: 2700-2708.

Dubuis C, Haas D. (2007). Cross-species GacA-controlled induction of antibiosis in pseudomonads. Appl Environ Microbiol 73: 650-654.

Dubuis C, Keel C, Haas D. (2007). Dialogues of rootcolonizing biocontrol pseudomonads. Eur J Plant Pathol 119: 311-328.

Farinha MA, Kropinsky AM. (1990). High efficiency electroporation of Pseudomonas aeruginosa using frozen cell suspensions. FEMS Microbiol Lett 58: 221-225.

Gamper M, Ganter B, Polito MR, Haas D. (1992). RNA processing modulates the expression of the $\operatorname{arc} D A B C$ operon in Pseudomonas aeruginosa. J Mol Biol 226: 943-957.

Gooderham JW, Hancock REW. (2009). Regulation of virulence and antibiotic resistance by two-component regulatory systems in Pseudomonas aeruginosa. FEMS Microbiol Rev 33: 279-294.

Goodman AL, Kulasekara B, Rietsch A, Boyd D, Smith RS, Lory S. (2004). A signaling network reciprocally regulates genes associated with acute infection and chronic persistence in Pseudomonas aeruginosa. Dev Cell 7: 745-754. 
Goodman AL, Merighi M, Hyodo M, Ventre I, Filloux A, Lory S. (2009). Direct interaction between sensor kinase proteins mediates acute and chronic disease phenotypes in a bacterial pathogen. Genes Dev 23: 249-259.

Haas D, Défago G. (2005). Biological control of soil-borne pathogens by fluorescent pseudomonads. Nat Rev Microbiol 3: 307-319.

Haas D, Keel C. (2003). Regulation of antibiotic production in root-colonizing Pseudomonas spp. and relevance for biological control of plant disease. Annu Rev Phytopathol 41: 117-153.

Hazelbauer GL, Falke JJ, Parkinson JS. (2008). Bacterial chemoreceptors: high-performance signaling in networked arrays. Trends Biochem Sci 33: 9-19.

Heeb S, Blumer C, Haas D. (2002). Regulatory RNA as mediator in GacA/RsmA-dependent global control of exoproduct formation in Pseudomonas fluorescens CHA0. J Bacteriol 184: 1046-1056.

Heeb S, Haas D. (2001). Regulatory roles of the GacS/GacA two-component system in plant-associated and other gram-negative bacteria. Mol Plant Microbe Interact 14: 1351-1363.

Heeb S, Valverde C, Gigot-Bonnefoy C, Haas D. (2005). Role of the stress sigma factor RpoS in GacA/RsmAcontrolled secondary metabolism and resistance to oxidative stress in Pseudomonas fluorescens CHA0. FEMS Microbiol Lett 243: 251-258.

Hunger K, Beckering CL, Marahiel MA. (2004). Genetic evidence for the temperature-sensing ability of the membrane domain of the Bacillus subtilis histidine kinase DesK. FEMS Microbiol Lett 230: 41-46.

Kay E, Dubuis C, Haas D. (2005). Three small RNAs jointly ensure secondary metabolism and biocontrol in Pseudomonas fluorescens CHA0. Proc Natl Acad Sci USA 102: 17136-17141.

Kay E, Humair B, Dénervaud V, Riedel K, Spahr S, Eberl L et al. (2006). Two GacA-dependent small RNAs modulate the quorum sensing response in Pseudomonas aeruginosa. J Bacteriol 188: 6026-6033.

Lapouge K, Schubert M, Allain FHT, Haas D. (2008). Gac/ Rsm signal transduction pathway of $\gamma$-proteobacteria: from RNA recognition to regulation of social behaviour. Mol Microbiol 67: 241-253.

Lapouge K, Sineva E, Lindell M, Starke K, Baker CS, Babitzke P et al. (2007). Mechanism of hcnA mRNA recognition in the Gac/Rsm signal transduction pathway of Pseudomonas fluorescens. Mol Microbiol 66: 341-356.

Laskowski MA, Kazmierczak BI. (2006). Mutational analysis of RetS, an unusual sensor kinase-response regulator hybrid required for Pseudomonas aeruginosa virulence. Infect Immun 74: 4462-4473.

Laville J, Voisard C, Keel C, Maurhofer M, Défago G, Haas D. (1992). Global control in Pseudomonas fluorescens mediating antibiotic synthesis and suppression of black root rot of tobacco. Proc Natl Acad Sci USA 89: 1562-1566.

Loper JE, Kobayashi DY, Paulsen IT. (2007). The genomic sequence of Pseudomonas fluorescens Pf-5: insights into biological control. Phytopathology 97: 233-238.

Mark GL, Morrissey JP, Higgins P, O'Gara F. (2006). Molecular-based strategies to exploit Pseudomonas biocontrol strains for environmental biotechnology applications. FEMS Microbiol Ecol 56: 167-177.

Mercado-Blanco J, Bakker PAHM. (2007). Interactions between plants and beneficial Pseudomonas spp.: exploiting bacterial traits for crop protection. Antonie van Leeuwenhoek 92: 367-389.

Miller JH. (1972). Experiments in Molecular Genetics. Cold Spring Harbor Laboratory Press: Cold Spring Harbor, NY.

Mondragón V, Franco B, Jonas K, Suzuki K, Romeo T, Melefors O et al. (2006). pH-dependent activation of the BarA-UvrY two-component system in Escherichia coli. J Bacteriol 188: 8303-8306.

Palmer DA, Bender CL. (1993). Effects of environmental and nutritional factors on production of the polyketide phytotoxin coronatine by Pseudomonas syringae pv. glycinea. Appl Environ Microbiol 59: 1619-1626.

Paulsen IT, Press CM, Ravel J, Kobayashi DY, Myers GS, Mavrodi DV et al. (2005). Complete genome sequence of the plant commensal Pseudomonas fluorescens Pf-5. Nat Biotechnol 23: 873-878.

Reimmann C, Valverde C, Kay E, Haas D. (2005). Posttranscriptional repression of GacS/GacA-controlled genes by the RNA-binding protein RsmE acting together with RsmA in the biocontrol strain Pseudomonas fluorescens CHA0. J Bacteriol 187: 276-285.

Rich JJ, Kinscherf TG, Kitten T, Willis DK. (1994). Genetic evidence that the gacA gene encodes the cognate response regulator for the $\operatorname{lem} A$ sensor in Pseudomonas syringae. J Bacteriol 176: 7468-7475.

Sambrook J, Russell DW. (2001). Molecular Cloning: A Laboratory Manual, 3rd edn. Cold Spring Harbor Laboratory Press: Cold Spring Harbor, NY.

Schmidt CS, Agostini F, Leifert C, Killham K, Mullins CE. (2004). Influence of soil temperature and matric potential on sugar beet seedling colonization and suppression of Pythium damping-off by the antagonistic bacteria Pseudomonas fluorescens and Bacillus subtilis. Phytopathology 94: 351-363.

Schnider-Keel U, Seematter A, Maurhofer M, Blumer C, Duffy B, Gigot-Bonnefoy C et al. (2000). Autoinduction of 2,4-diacetylphloroglucinol biosynthesis in the biocontrol agent Pseudomonas fluorescens CHA0 and repression by the bacterial metabolites salicylate and pyoluteorin. J Bacteriol 182: 1215-1225.

Shanahan P, O'Sullivan DJ, Simpson P, Glennon JD, O’Gara F. (1992). Isolation of 2,4-diacetylphloroglucinol from a fluorescent pseudomonad and investigation of physiological parameters influencing its production. Appl Environ Microbiol 58: 353-358.

Slininger PJ, Shea-Wilbur MA. (1995). Liquid-culture pH, temperature, and carbon (not nitrogen) source regulate phenazine productivity of the take-all biocontrol agent Pseudomonas fluorescens 2-79. Appl Microbiol Biotechnol 43: 794-800.

Stanisich VA, Holloway BW. (1972). A mutant sex factor of Pseudomonas aeruginosa. Genet Res 19: 91-108.

Valverde C, Heeb S, Keel C, Haas D. (2003). RsmY, a small regulatory RNA, is required in concert with RsmZ for GacA-dependent expression of biocontrol traits in Pseudomonas fluorescens CHA0. Mol Microbiol 50: 1361-1379.

Valverde C, Lindell M, Wagner EG, Haas D. (2004). A repeated GGA motif is critical for the activity and stability of the riboregulator RsmY of Pseudomonas fluorescens. J Biol Chem 279: 25066-25074.

Ventre I, Goodman AL, Valley-Gely I, Vasseur P, Soscia C, Molin S et al. (2006). Multiple sensors control reciprocal expression of Pseudomonas aeruginosa regulatory RNA and virulence genes. Proc Natl Acad Sci USA 103: 171-176. 
Vieira J, Messing J. (1991). New pUC-derived cloning vectors with different selectable markers and DNA replication origins. Gene 100: 189-194.

Voisard C, Bull CT, Keel C, Laville J, Maurhofer M, Schnider U et al. (1994). Biocontrol of root diseases by Pseudomonas fluorescens CHA0: current concepts and experimental approaches. In: O’Gara F, Dowling DN, Boesten B (eds). Molecular Ecology of Rhizosphere Microorganisms. VCH: Weinheim, Germany. pp 67-89.
Workentine ML, Chang L, Ceri H, Turner RJ. (2009). The GacS-GacA two-component regulatory system of Pseudomonas fluorescens: a bacterial two-hybrid analysis. FEMS Microbiol Lett 292: 50-56.

Zuber S, Carruthers F, Keel C, Mattart A, Blumer C, Pessi G et al. (2003). GacS sensor domains pertinent to the regulation of exoproduct formation and to the biocontrol potential of Pseudomonas fluorescens CHA0. Mol Plant Microbe Interact 16: 634-644.

Supplementary Information accompanies the paper on The ISME Journal website (http://www.nature.com/ismej) 